\title{
GESTÃO DA QUALIDADE NA INDÚSTRIA TORREFADORA DE CAFÉ NA REGIÃO SUDESTE DO BRASIL: UMA ANÀLISE DE CUSTO ${ }^{1}$
}

\author{
Eduardo Vitor de Paula ${ }^{2}$ \\ Marília Fernandes Maciel Gomes ${ }^{3}$ \\ Aziz Galvão da Silva Junior ${ }^{3}$
}

Resumo - O segmento torrefador vem sofrendo profundas transformações desde o início da década de 90, e o quesito qualidade tem sido imprescindível para a atuação dessas empresas no mercado. A qualidade tem desempenhado importante papel para o desempenho das organizações. Alguns autores afirmam que, sob a égide da globalização de mercados, a qualidade atinge seu patamar máximo como condicionante das decisões de negócios e passa a ser o passaporte para abertura dos mercados mais exigentes e para manutenção dos nichos de mercados mais disputados. Contudo, sistemas ou programas de qualidade geram custos que, na maioria das vezes, são ignorados pelas empresas. No Brasil, a literatura sobre os custos da qualidade carece de estudos mais detalhados. Este trabalho objetivou avaliar os custos da qualidade na indústria torrefadora de café na região Sudeste do Brasil, em relação a alguns indicadores de desempenho, mais detidamente sobre aquelas empresas que adotam algum programa de qualidade em seu processo produtivo. Os resultados apontam que somente alguns indicadores de desempenho melhoraram em relação aos custos e que as empresas não têm um sistema definido de mensuração dos custos da qualidade.

Palavras-Chave: Gestão da qualidade, custos da qualidade, indústria torrefadora de café.

\footnotetext{
${ }^{1}$ Recebido em 26/02/2004. Aceito em 31/03/2004.

${ }^{2}$ M.S. Economia Aplicada pelo Departamento de Economia Rural - UFV- Viçosa- Analista do Banco Central do Brasil - E-mail: eduardopaula@bcb.gov.br

${ }^{3}$ Professores Doutores do Departamento de Economia Rural - Universidade Federal de Viçosa - mfmgomes@.ufv.br, E-mail: aziz@ufv.br
} 


\section{Introdução}

$\mathrm{Na}$ atual conjuntura econômica mundial, em que se têm observado a consolidação de esforços pela desregulamentação dos mercados e a ampliação dos processos de integração comercial entre países, são requeridos das empresas participantes desse mercado ajustes constantes, para que elas venham a manter e, ou, conquistar competitividade.

Nesse contexto, muitos setores da economia brasileira têm buscado adequar-se a esse novo mercado, que se apresenta cada vez mais exigente, razão por que as suas empresas implementam medidas de ajustes internos a padrões reconhecidos por potenciais clientes, ou seja, adotam um conjunto de normas de qualidade que seja reconhecido mundialmente.

A adoção de um programa de qualidade surgiu para conferir competitividade às empresas no ramo em que atuam. Oferecer produtos com certificação de qualidade, mantendo ou até mesmo diminuindo os custos de produção, é a única alternativa para a sobrevivência das empresas.

As empresas brasileiras torrefadoras de café torrado e moído, objeto de análise deste estudo, encontram-se dentre as empresas dos diferentes segmentos que almejam atingir essa meta, razão pela qual é necessário que estas passem por reformulações, em termos de qualificação e certificação.

A indústria torrefadora de café é um segmento tradicional da agroindústria brasileira, composta por várias empresas e diversas marcas, e dedica-se basicamente ao mercado interno.

Segundo Vegro (1993), na primeira parte da década de 90, as torrefadoras voltadas essencialmente para o abastecimento do mercado interno já iniciavam um novo período de atuação empresarial. O setor passou a incorporar padrões competitivos comuns entre indústrias alimentícias de outros ramos produtivos, os quais passaram a conferir a essas empresas poder de concorrência e penetração no mercado externo. 
Dentre as mudanças ocorridas no setor, segundo Zylbersztajn (1992), a principal estratégia concorrencial engendrada entre as empresas, no ramo de torrefação e moagem, foi a diferenciação e segmentação do mercado. Segundo esse autor, a desregulamentação interna do mercado tem promovido aumento na competição entre as empresas, com prevalência daquelas de maior escala e mais ágeis na implantação e capacitação para controle de custos, qualidade total, política de recursos humanos, "marketing" dos produtos diferenciados, verticalização e integração modernizadora das atividades comerciais.

Segundo Saes e Farina (1999), com a desregulamentação do setor por parte do governo federal, as empresas torrefadoras têm se defrontado com rápidas mudanças no seu ambiente competitivo. O sistema agroindustrial do café enfrentou o fim do Acordo Internacional, que, por décadas, disciplinou o mercado cafeeiro, em que predominava, historicamente, uma forte regulamentação estatal. $\mathrm{O}$ mercado passou, no início dos anos 90, por várias mudanças com a extinção do IBC (Instituto Brasileiro do Café), dentre as quais se destaca o crescimento da demanda, que foi uma das mais importantes conquistas da indústria nos últimos anos. A tendência decrescente do consumo per capita de café, que se verificava no início da década de 90, conseguiu ser revertida, e isso se explica, em parte, pela melhoria da imagem de má qualidade do café entre os consumidores brasileiros.

Na implementação de programas de qualidade são identificadas algumas fases no que diz respeito aos custos. Segundo Weindlmaier (1996), os custos da qualidade podem ser mensurados dentro da empresa e subdividem-se em Custos da Administração da Qualidade e Custos das Falhas. O Custo de Administração divide-se em custos da prevenção de defeitos e custos de inspeção e testes, enquanto os Custos das Falhas, em custos das falhas internas e externas. É importante salientar que os custos das falhas externas são de difícil mensuração, uma vez que ocorrem fora da empresa, quando o produto já se encontra no mercado. As empresas não conseguem dimensionar o quanto perdem, ao deixar que produtos defeituosos cheguem ao mercado. 
A literatura sobre custos da qualidade ainda é incipiente. Para Wernke (1999), os conceitos de custos da qualidade passaram a ser disseminados na bibliografia que tratava do controle da qualidade e buscava oferecer suporte às ações de melhorias, além de tentar medir a qualidade nas empresas.

No início dos anos 90, diversos setores da economia passaram a adotar as normas da série ISO 9000, dado o sucesso dos programas de qualidade total em empresas de outros países. No entanto, a atenção foi dada somente aos possíveis resultados que os programas poderiam vir a alcançar. Indagações sobre os custos de implantação desses programas ficaram em plano secundário e não há estudos pormenorizados acerca dos custos de implantação dos programas. Alguns estudos foram realizados em algumas universidades e institutos, contudo, o problema dos custos da qualidade ainda carece de estudos específicos (Feigenbaum, 1994; Crosby, 1994; Weindlmaier,1996; Frota,2000).

Frota (2000), um dos estudiosos iniciais da teoria da qualidade, salientou que a adoção de programas de qualidade gera a função qualidade de uma empresa, definida como um conjunto de atividades que abrange todos os setores da empresa, de forma direta e indireta, com o objetivo de melhorar a qualidade do produto final e manter consistente essa melhoria. Para esse autor, a função qualidade abrange toda a empresa, pois esta é tarefa de cada setor.

Os custos totais operacionais da qualidade, no entanto, não representam apenas a soma de dinheiro gasto pela função qualidade. Não são apenas os elementos que têm ação positiva sobre a qualidade que geram custos; tudo o que é negativo e destruidor para a qualidade também gera custo e, na maioria das vezes, custos maiores do que é gasto efetivamente. Os custos operacionais totais da qualidade podem ser definidos como tudo o que é despendido pela função qualidade, somado aos custos resultantes do que ocorre quando essa função falha (Frota, 2000).

Diante desse contexto, este trabalho objetivou avaliar os custos da qualidade no setor torrefador de café da região Sudeste do Brasil, em rela- 
ção a alguns indicadores de desempenho, como produtividade, lucratividade, faturamento bruto anual, retorno sobre investimentos, participação de mercado e custos de produção, e ainda verificar em qual fase de implantação dos programas de qualidade as empresas incorrem em maiores custos. Pretende-se ainda verificar a participação dos custos da qualidade no custo total das empresas. O trabalho focaliza as análises daquelas empresas que adotam programas de qualidade em seu processo produtivo.

\section{Metodologia}

\subsection{Teoria da qualidade}

A mensuração dos custos da qualidade foi introduzida por Feigenbaum, que, em seu trabalho, salientou que a forma de medir os custos da qualidade é por meio da não-qualidade, ou seja, mensurar aquilo que a empresa deixa de produzir ou perde quando não adota programas de qualidade (Silva Júnior, 2000 a). De acordo com Crosby (1994), o custo da qualidade é a única maneira válida de a empresa medir os sucessos de um programa de qualidade.

Segundo Weindlmaier (1996), esses custos podem ser mensurados dentro da empresa e subdividem-se em custos da administração da qualidade e custos das falhas. Dentro dos custos de administração, têm-se:

- Custos da prevenção de defeitos - Esse custo englobaria os seguintes itens: planejamento da qualidade, inspeção desse planejamento, auditoria, administração do sistema de qualidade, treinamento e avaliação de desempenho;

- Outros custos - Inspeção e testes, inspeção final e testes, inspeções específicas e testes. 
Na composição dos custos das falhas têm-se os custos da falhas internas e os das falhas externas:

- Os custos das falhas internas englobam reprocessos, retrabalho, refugos, novos testes, análises das falhas, quantidades de peças fora dos padrões, heterogeneidade de produtos.

- Os custos das falhas externas são subdivididos em operacionais e estratégicos e são advindos dos defeitos ou danos causados quando o produto já está no mercado.

No enfoque moderno de Gestão da Qualidade, os custos externos têm grande importância. Aqui, são incluídos os custos relacionados com insatisfação do consumidor e decorrentes dos efeitos negativos do produto e processo na sociedade. Tais custos são de difícil mensuração e têm efeitos concentrados no médio e longo prazo (Silva Júnior, 2000 b). A Figura 1, a seguir, ilustra a situação descrita.

Nota-se, na Figura 1, que os custos no longo prazo são difíceis de serem mensurados, visto que ocorrem quando o produto já está no mercado, e torna-se difícil para a empresa precisar o quanto ela perdeu, ou está perdendo, por ter cometido uma falha durante o processo produtivo.

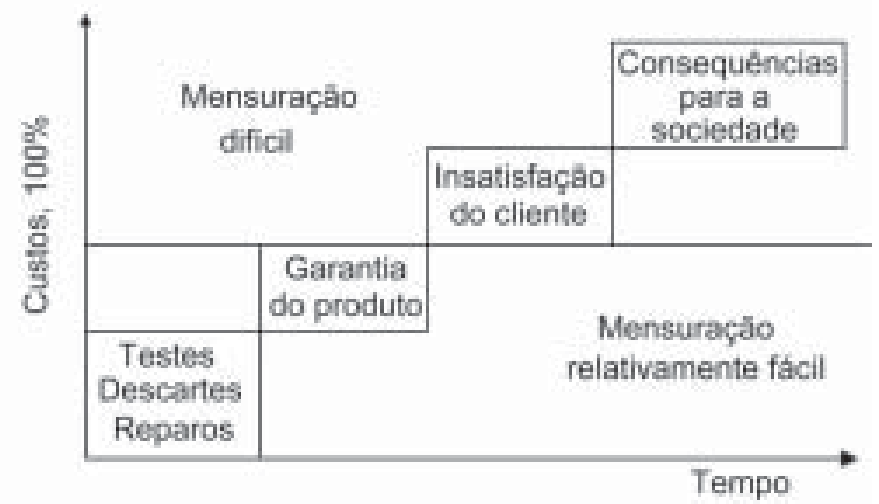

Fonte: Silva Júnior (2000 b).

Figura 1 - Custos relacionados com qualidade. 
De maneira geral, pode-se deduzir a estrutura dos custos operacionais totais da qualidade, de acordo com o Quadro 1 proposto por Frota (2000).

Quadro 1 - Estrutura dos custos operacionais totais da qualidade

\begin{tabular}{|c|c|c|c|c|c|c|c|c|}
\hline $\begin{array}{l}\text { Estrutura de } \\
\text { custos }\end{array}$ & $=$ & \begin{tabular}{|ll} 
Custos & da \\
função & \\
qualidade &
\end{tabular} & + & \multicolumn{5}{|c|}{$\begin{array}{l}\text { Custos que ocorrem quando a função } \\
\text { qualidade falha }\end{array}$} \\
\hline \multirow[t]{2}{*}{\begin{tabular}{|l|}
$\begin{array}{l}\text { Custos } \\
\text { operacionais }\end{array}$ \\
\end{tabular}} & $=$ & Prevenção & + & Avaliação & + & $\begin{array}{l}\text { Falhas } \\
\text { internas }\end{array}$ & + & $\begin{array}{l}\text { Falhas } \\
\text { externas }\end{array}$ \\
\hline & $=$ & 5 a $15 \%$ & + & 20 a $25 \%$ & + & \multicolumn{3}{|c|}{65 a $70 \%$ do total } \\
\hline $\begin{array}{l}\text { Custos totais } \\
\text { da qualidade }\end{array}$ & $=$ & $\begin{array}{l}\text { Custos da } \\
\text { qualidade }\end{array}$ & + & \multicolumn{5}{|c|}{ Custos da má-qualidade } \\
\hline $\begin{array}{l}(10 \text { a } 40 \% \\
\text { das vendas) }\end{array}$ & $=$ & \begin{tabular}{|l|} 
Custos \\
controláveis \\
pela gerência
\end{tabular} & + & \multicolumn{5}{|c|}{ Custos não-controláveis pela gerência } \\
\hline Total & $=$ & Investimentos & + & \multicolumn{5}{|c|}{ Perdas e prejuízos } \\
\hline
\end{tabular}

Fonte: Frota (2000).

De acordo com o Quadro 1, os custos totais da qualidade correspondem à soma dos custos da qualidade mais os custos que incidem quando a função qualidade falha. Os custos efetivos da qualidade, controláveis pela gerência, geralmente situam-se entre 15 a $20 \%$ do custo total, e o restante decorre das falhas da não-qualidade. O Quadro 1 revela, ainda, que os custos efetivos podem ser considerados como investimentos, enquanto os decorrentes da não-qualidade são contabilizados como perda ou prejuízo.

\subsection{Mensuração dos custos da qualidade}

Os modelos para os custos da qualidade, primeiramente, foram desenvolvidos por Juran e Gryna (1991). A Figura 2a apresenta o primeiro 
modelo, que prevaleceu por muito tempo. Esse modelo retrata o caso em que a prevenção e a execução realizadas por seres humanos falíveis, incapazes de se concentrarem $100 \%$ do tempo, limitavam os esforços para se obter a perfeição, a custos finitos. Desse modo, a curva de prevenção mais avaliação cresce ao infinito à medida que se aproxima da perfeição, conseqüentemente, também sobe a curva de custo total. No segundo modelo, Figura 2b, que ilustra os tempos atuais, com substituição do homem pela máquina e, inclusive, com a inclusão de inspeção e testes de produtos, a redução de defeitos pode ser alcançada a custos mensuráveis.

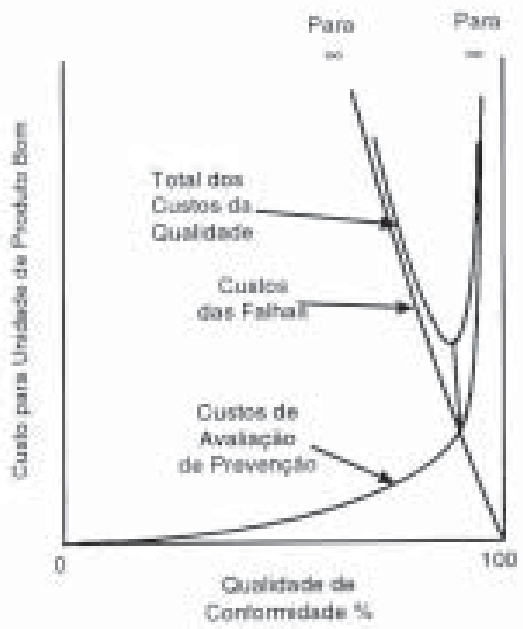

(a)

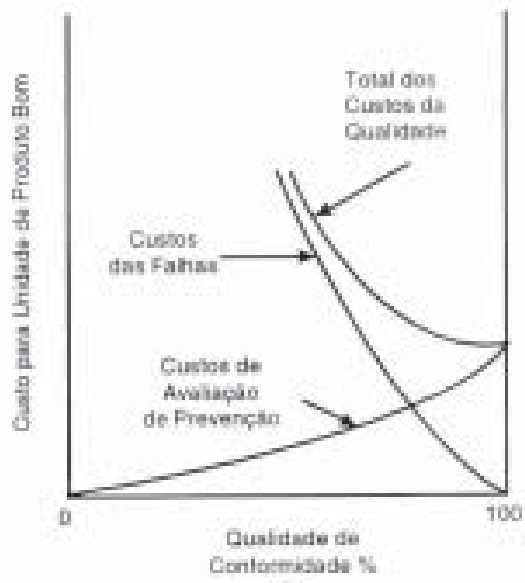

(b)

Fonte: Juran e Gryna, (1991).

Figura 2 - Modelo clássico dos custos ótimos da qualidade (a) e novo modelo dos custos ótimos da qualidade (b).

Juran e Gryna (1991) mostraram que é possível controlar os custos da qualidade e, simultaneamente, garantir a produção livre de defeitos. Contudo, salientaram que é preciso que as empresas tenham rígido controle de cada fase dos custos da qualidade. 
O comportamento do custo total, à medida que havia mudanças nos recursos despendidos em cada fase do processo produtivo, pode ser visualizado na Figura 3. No início do processo produtivo, quando não se dava a devida atenção à prevenção de defeitos, tinha-se alto custo decorrente das falhas. À medida que o processo produtivo caminhava havia aumento nos dispêndios com prevenção e, conseqüentemente, redução nos custos das falhas. Nessa etapa, o custo total da qualidade atingia o seu ponto mínimo, a partir do qual o custo total da qualidade voltava a crescer. Nesse estágio tinha-se alto custo de avaliação e redução dos custos das falhas, o que proporcionava uma produção livre de defeitos.

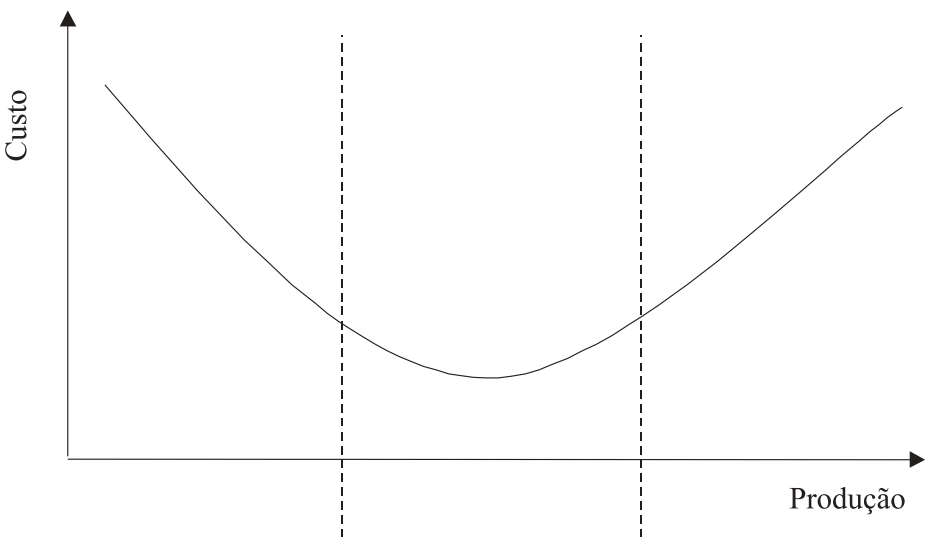

\begin{tabular}{l|l|l}
\hline $\begin{array}{l}\text { Zona de projeto de aperfeiçoamento } \\
\text { (melhoria) }\end{array}$ & Zona de indiferença & Zona de alto custo de avaliação \\
\hline $\begin{array}{l}\text { Custos das falhas }>70 \% \\
\text { Prevenção }<10 \%\end{array}$ & $\begin{array}{l}\text { Custos das falhas 50\% } \\
\text { Prevenção } 10 \%\end{array}$ & $\begin{array}{l}\text { Custos das falhas }<40 \% \\
\text { Avaliação }>50 \%\end{array}$ \\
\hline Localização de projetos de pesquisa & $\begin{array}{l}\text { Deslocamento de ênfase } \\
\text { para o controle }\end{array}$ & Inspeção \\
\hline $100 \%$ de defeito & $\begin{array}{l}\text { Qualidade de } \\
\text { conformidade }\end{array}$ & $100 \%$ livre de defeitos \\
\hline
\end{tabular}

Fonte: Juran (1996).

Figura 3 - Zonas de melhorias da qualidade e sua relação com os custos da qualidade. 


\subsection{Procedimento analítico}

Na determinação dos custos da qualidade utilizou-se o modelo proposto por Juran (1996), que considerou diferentes custos em diferentes fases do processo produtivo, quais sejam, custo da prevenção, avaliação e falhas internas. Procurou-se determinar, em termos percentuais, dentre as fases citadas, qual o dispêndio da empresa em cada uma das categorias.

Na investigação da participação dos custos da qualidade no custo total das empresas adotantes de um programa de controle de qualidade total e, ou, gerenciamento da qualidade total, procurou-se fazer uma análise comparativa em que se consideraram dois períodos distintos, antes e depois da adoção do programa.

Buscou-se, por último, verificar o comportamento do custo de qualidade, em relação a alguns indicadores de desempenho de uma empresa, como produtividade, lucratividade, faturamento bruto anual, retorno sobre investimento, participação de mercado e custo de produção, ou seja, tentou-se averiguar se os programas de controle de qualidade total e, ou, gerenciamento da qualidade total foram eficazes em reduzir os custos de qualidade e, simultaneamente, promover melhorias nos indicadores de desempenho.

Para fins deste trabalho, foi feito o cálculo das médias dos indicadores e obtidas as respectivas diferenças de médias em relação ao custo da qualidade. Os indicadores foram mensurados por meio da Escala de Likert ${ }^{4}$, de sete postos, que variaram de $(-3)$, com resposta desfavorável acerca do item pesquisado (reduziu/piorou muito), até (3), resposta favorável (aumentou/melhorou muito). Essa escala é utilizada para transformar opiniões em variáveis mensuráveis.

\footnotetext{
${ }^{4}$ Uma escala Likert, proposta por Rensis Likert em 1932, é uma escala em que os respondentes são solicitados a concordarem ou discordarem das afirmações e também informarem qual o seu grau de concordância/discordância com elas. A cada resposta é atribuído um número que reflete a direção da atitude do respondente em relação a cada afirmação.
} 


\subsection{Fonte de dados e amostra}

Os dados utilizados neste trabalho foram obtidos de questionários enviados por via postal. O objeto de estudo foi a indústria torrefadora de café da região Sudeste do Brasil. A amostra estudada foi obtida nos estados de São Paulo e Minas Gerais, cuja escolha se deu em razão de 86,3\% dessas empresas torrefadoras estarem concentradas em seus territórios, o que tornou a amostra representativa da população de empresas torrefadoras de café na região Sudeste do Brasil.

\subsubsection{Amostra}

Para caracterização da amostra das empresas torrefadoras de café na região Sudeste do Brasil, estas foram divididas em dois grupos (1 e 2), como forma de facilitar as análises de algumas características e indicadores em estudo. $\mathrm{O}$ grupo 1 representa empresas que não utilizam nenhum programa de qualidade; o grupo 2, aquelas que utilizam algum programa de gerenciamento ou controle da qualidade total.

Salienta-se que, das $42^{5}$ empresas estudadas, apenas 12 adotavam algum programa de gerenciamento ou controle da qualidade; as demais não tinham nenhum tipo de programa. Esse número de empresas que adotavam programas de qualidade respalda a percentagem com a qual o fenômeno se verifica na determinação da amostra, que, a priori, foi cerca de 5\%, levando-se em consideração as 290 empresas componentes da população de torrefadoras.

${ }^{5}$ Maiores informações, ver PAULA (2002). 


\section{Resultados}

\subsection{Categoria dos custos da qualidade com que as empresas reali- zam os maiores dispêndios}

Este tópico aborda as categorias do custo da qualidade no qual as empresas realizam os maiores investimentos, subdivididas em Custos de Prevenção, Falhas e Avaliação.

De acordo com a teoria dos custos da qualidade, quando se aumentam os custos com prevenção, ocorre redução nos custos com falhas internas e avaliação. Foi questionado às empresas adotantes de programas de qualidade em qual categoria de custos da qualidade elas realizavam maiores investimentos. A Figura 4, a seguir, apresenta os resultados.

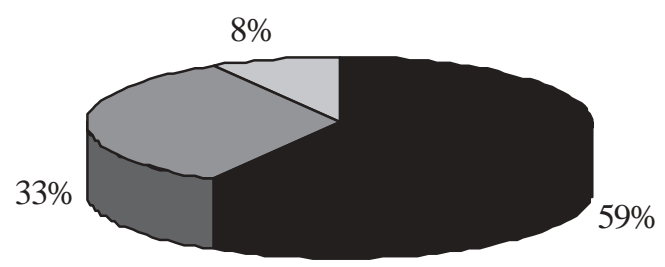

— prevenção $\square$ avaliação $\square$ falhas internas

Figura 4 - Categoria dos custos da qualidade na qual as empresas do Grupo 2 realizam maiores investimentos.

Os resultados apontam que grande parte das empresas torrefadoras adotantes de algum programa de qualidade, 7 empresas (59\%), realizava maiores investimentos na prevenção. Assim, ao aumentar os custos com prevenção, os montantes de recursos destinados à avaliação e falhas internas tendiam a se reduzir. A prevenção diz respeito ao combate dos fatores que podem causar algum malefício ao produto, durante o proces- 
so produtivo. Nas torrefadoras de café, especificamente, os gastos com prevenção são destinados às seções de torrefação e acondicionamento do produto (empacotamento); a torrefação diz respeito ao ponto de torra, eliminação de gases poluentes e também ao treinamento de recursos humanos. No empacotamento, os gastos se concentram na embalagem propriamente dita e nas oscilações de peso do produto durante o acondicionamento nas embalagens.

Os custos com avaliação dizem respeito ao interrompimento do funcionamento dos equipamentos para inspeção, reavaliação de funcionários e constante acompanhamento de demais fatores que podem vir a causar falhas. Os custos das falhas internas são decorrentes da produção que sai com algum defeito, como embalagens fora da especificação e produto com alguma irregularidade, como ponto de torra e granulometria.

Nota-se que, quando as empresas concentram seus esforços na prevenção, todas as demais causas são reduzidas ou eliminadas, o que acarreta, na maioria das vezes, uma produção livre de defeitos. A eliminação dessas causas, por consequiência, reduz os custos com avaliação e com falhas internas.

\subsection{Participação dos custos da qualidade no custo total das empre- sas adotantes de programas de qualidade}

Nesta parte do trabalho, verificou-se a participação dos custos da qualidade no custo total das empresas que adotam algum programa de qualidade. Autores como Crosby (1994) revelaram que uma das formas de se avaliar a eficácia de um programa de qualidade é conhecer e mensurar os custos da qualidade. De acordo com Feigenbaum, citado por Robles Júnior (1996), esses custos poderiam ser equiparados, em importância, a outras categorias de custos, como, por exemplo, custos com mão-deobra, com engenharia e com vendas. Contudo, a realidade é que a maioria dos programas de qualidade existentes falha ao desenvolver o controle de custos juntamente com ações de melhorias. 
Para Coral (1996), não pode haver dissociação entre o controle de custos da qualidade e os programas propriamente ditos. Programas de controle de custos e programas de qualidade têm sido utilizados separadamente, sem o reconhecimento de que a interação de custos e qualidade é fundamental para o sucesso operacional e econômico da organização.

Procurou-se, mediante questionário enviado às empresas, investigar a participação do custo da qualidade no custo total de produção, antes e após as empresas adotarem os programas de qualidade. O intuito foi descobrir se, após a adoção de programas de qualidade, ocorreu redução dos custos da qualidade em relação ao custo total de produção. Sobre essa questão, apenas $42 \%$ das empresas responderam, e a totalidade das respostas apresentou percentual de 1 a $10 \%$, parte que representa o custo da qualidade sobre o custo total das empresas antes da implantação dos programas.

Após a implantação dos programas, foi colocada a mesma escala de valores para a resposta. Verificou-se que, após a implantação do programa, $100 \%$ das empresas responderam que não houve redução da participação do custo da qualidade no custo total de produção, ficando a resposta na mesma escala anterior, ou seja, 1 a 10\% dos custos da qualidade em relação aos custos totais.

Pode-se concluir, diante da situação averiguada e com base em dois argumentos, que as empresas não têm controle formalizado nos custos com produção e nos custos com qualidade, ou que os programas de qualidade têm falhado na sua missão de reduzir os custos com qualidade durante o processo produtivo da empresa. $\mathrm{O}$ primeiro argumento é mais sólido, uma vez que quase $60 \%$ das empresas adotantes de programas de qualidade desconhecem os custos da qualidade e, obviamente, a participação desses custos nos seus custos totais de produção. Em seu trabalho para a indústria de diversos setores da região Sul do Brasil, Soares (1999) constatou que as empresas, de maneira geral, não mensuram esses custos, o que, na maior parte das situações, compromete uma real avaliação da eficácia dos programas de qualidade adotados. 


\subsection{Comportamento dos custos da qualidade em relação aos indi- cadores de desempenho}

Analisa-se, neste tópico, o comportamento dos custos da qualidade em relação aos indicadores de desempenho das empresas que adotam algum programa de qualidade. O objetivo é verificar se, ao mesmo tempo que se tem redução dos custos da qualidade, há também melhorias nos indicadores de desempenho. Os programas de qualidade, segundo Deming (1982), quando são implementados com eficácia, têm a propriedade de reduzir os custos da qualidade e ainda promover melhorias nos demais indicadores de desempenho. De acordo com Coral (1996), o gerenciamento dos custos da qualidade, por meio do controle ou do gerenciamento de processos, pode levar as empresas a aumentar a lucratividade, melhorar a qualidade e aumentar a fatia de mercado. Espera-se que, com a redução dos custos da qualidade, haja melhora efetiva nos indicadores de desempenho das empresas torrefadoras.

Com vistas em averiguar se os programas de qualidade foram eficazes em reduzir os custos da qualidade e, simultaneamente, promover melhorias nos indicadores de desempenho, foi feito o cálculo das médias dos indicadores e obtidas as respectivas diferenças de médias em relação aos custos da qualidade. Os indicadores foram mensurados com base em uma escala de Likert, em que os postos variaram de (-3) a (3), passando por (0). Os valores positivos indicam respostas favoráveis e os negativos, respostas desfavoráveis. A Tabela 1 ilustra os resultados. 
Tabela 1 - Valores das médias dos indicadores mensurados de acordo com a escala Likert e com as respectivas diferenças em relação aos custos da qualidade

\begin{tabular}{lccc}
\hline \multicolumn{1}{c}{ Indicadores } & $\begin{array}{c}\text { Médias dos } \\
\text { indicadores }\end{array}$ & $\begin{array}{c}\text { Média dos custos } \\
\text { da qualidade }\end{array}$ & Diferenças \\
\hline Produtividade & 1,41 & 0,66 & 0,75 \\
Lucratividade & 0,75 & 0,66 & 0,09 \\
Fat. bruto anual & 0,5 & 0,66 & $-0,16$ \\
Ret. investimentos & 0,41 & 0,66 & $-0,24$ \\
Part. de mercado & 0,91 & 0,66 & 0,25 \\
Cus. de produção & 0,75 & 0,66 & 0,09 \\
\hline
\end{tabular}

Fat $=$ Faturamento bruto anual; Ret $=$ Retorno sobre investimento; Part $=$ Participação de mercado; Cus $=$ Custos de produção.

Fonte: Dados da pesquisa.

De acordo com as diferenças de médias entre o custo da qualidade e os demais indicadores, os programas de qualidade mostraram-se eficazes na melhoria dos indicadores, de acordo com a Teoria da Qualidade, excetuando-se dois indicadores. Os indicadores faturamento bruto anual e retorno sobre os investimentos não apresentaram melhorias em relação aos custos da qualidade. As empresas têm melhor percepção dos indicadores que estão atrelados ao processo produtivo diretamente, fato que pode explicar a não melhoria desses indicadores em relação aos custos da qualidade, uma vez que estes requerem um período de tempo maior para que seja avaliada a sua evolução. Verificadas a redução nos custos da qualidade e a melhoria nos indicadores, poder-se-ia afirmar que os programas de qualidade foram eficazes nas empresas torrefadoras, para as quais os programas mostraram-se eficazes nos indicadores em que as empresas podem fazer rápidas avaliações de sua evolução, em relação aos custos da qualidade. 


\section{Conclusão}

Conclui-se que as empresas torrefadoras não têm um sistema definido para a mensuração dos custos da qualidade. Ao implantar os programas, elas estão preocupadas com os resultados práticos destes, ficando a questão dos custos da qualidade como objetivo secundário. As empresas fazem avaliações precisas daqueles indicadores que requerem menor tempo na sua evolução, fato que pode prejudicá-las na observação dos custos da qualidade, já que a mensuração destes pode requerer um período de tempo maior. Os programas de qualidade só se tornarão eficazes se as empresas introduzirem um sistema de acompanhamento de controle dos custos da qualidade, pois a implantação do programa, por si, não garante a melhoria dos indicadores, e a mensuração dos custos da qualidade é uma questão-chave para a eficácia dos programas.

\section{Referências bibliográficas}

CORAL, E. Avaliação e gerenciamento dos custos da não-qualidade. Florianópolis. UFSC, 1996. 128 p. Tese (Doutoramento em Engenharia da Produção), Universidade Federal de Santa Catarina, 1996.

CROSBY, P. B. Qualidade é investimento. 6 ${ }^{\text {a }}$. ed. Rio de Janeiro: José Olympio, 1994. 327 p.

DEMING, W. E. (1982): Quality, productivity and competitive position. Cambridge.

FEIGENBAUM, A . V. Controle da qualidade total. $1^{\text {a }}$. edição São Paulo: Makron Books, 1994, v.1 205 p.

FROTA, A. O barato sai caro. Universidade Federal da Bahia. 2000. (mimeo). 9p. 
JURAN, J. M; GRYNA, F. M. Controle de qualidade handbook. Tradução de Maria Cláudia de Oliveira Santos. S.P. Makron Books, McGraw - Hill, v.1. 1991.

PAULA, E. V. Programas de qualidade e sua influência nos indicadores de desempenho da indústria torrefadora de café na região sudeste do Brasil. Viçosa: UFV, 2002. 99 p. Dissertação (Mestrado em Economia Rural) - Universidade Federal de Viçosa, 2002.

ROBLES JUNIOR, A. Custos da Qualidade. Uma estratégia para a competição global. 1 $^{\text {a }}$. Ed. São Paulo. Editora Atlas 1996, 135 p.

SAES, M. S. M.; FARINA, E.M.M.Q. O agribusiness do café no Brasil. São Paulo: Instituto de Pesquisa Econômica Aplicada, IPEA, PENSA, USP, 1999. 230 p.

SIEGEL, S. Estatística não-paramétrica para as ciências do comportamento. $2^{\text {a }}$.ed. São Paulo: McGraw-Hill do Brasil, 1979. 350p.

SILVA JÚNIOR (a), ALBERTO GOMES. Programas de qualidade e o comportamento de indicadores de desempenho da indústria de abate e processamento de suínos na região centro-sul do Brasil. Viçosa: UFV, 2000. 134 p. Dissertação (Mestrado em Economia Rural) - Universidade Federal de Viçosa, 2000.

SILVA JÚNIOR (b), AZIZ GALVÃO. Gestão da qualidade. Universidade Federal de Viçosa, 2000. (mimeo). 66 p.

SOARES, A. C. S. Qualidade: estratégia de competitividade industrial -uma análise na indústria sul brasileira. Florianópolis: UFSC, 1999. 122p. Dissertação (Mestrado em Engenharia da Produção) Universidade Federal de Santa Catarina, 1999.

VEGRO, C.L.R. O café robusta capixaba frente a crise: a crise internacional do café e a reestruturação técnico-produtiva e comercial do segmento robusta capixaba. São Paulo: CIRAD/PROTER, 1993. 29 p. 
WEINDLMAIER, H. Significance, possibilities and problems of the assessment of quality related costs in food enterprises. In: Quality Management and Process Improvement for Competitive Advantage in Agriculture Food. Vol. 1. Edited by G.Schifer and R. Helbig. München, Germany. 1996, 9p.

\title{
WERNKE, R. Relatório para acompanhamento e controle dos cus- tos da qualidade. CRCRS. N. ${ }^{\circ}$ 99, dez de 1999.
}

ZYLBERSZTAJN, D.; FARINA, E. O sistema agroindustrial do café análise e estratégia - Relatório Final. São Paulo: [s. n.], 1992. v. I e II, $350 \mathrm{p}$.

\begin{abstract}
The coffee roasting segment is passing through deep transformation since the beginning of the 90's, and the requirement of quality has been essential for the performance of those companies in the market. The quality factor has been playing important role for the competitiveness of the enterprises. Some authors believe that, under the aegis of the market globalization, the quality reaches its highest level of importance in the business decision process and turns out to be the passport for opening the most challenging markets and for upholding the niches in the more competitive markets. However, systems or quality programs generate costs that, usually, are unknown for the firms. In Brazil, the literature on the costs of the quality lacks more comprehensive studies. This paper aims to evaluate the costs of the quality in the coffee roasting industry in the Southeast of Brazil, in relation to some performance indicators, intended for those companies that adopt some quality program in its industrious process. The results point to that only some performance indicators get better in relation to the costs and that the companies don't have a defined system of their cost measurements of the quality.
\end{abstract}

Key-Words: Management quality, costs of the quality, coffee roasting industry. 
REVISTA DE ECONOMIA E AGRONEGÓCIO, VOL.2, No 1 